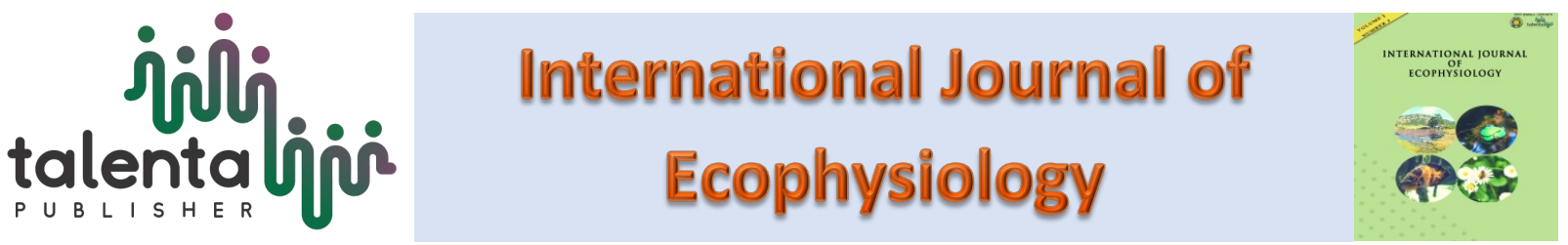

\title{
THE EFFECT OF THE QUALITY OF Morus australis LEAVES ON THE NUTRITION INDEX of Bombyx mori L.
}

\author{
Masitta Tanjung $^{1^{*}}$, Rildah Novianty Daulay ${ }^{2}$, and Nursal ${ }^{1}$ \\ ${ }^{1}$ Lecturer at the Department of Biology, Faculty of Mathematics and Natural Sciences, Universitas \\ Sumatera Utara. Jln. Biotechnology No. 1, USU Campus, Padang Bulan Medan, North Sumatra 2015 \\ Undergraduate student of the Department of Biology, Faculty of Mathematics and Natural Sciences, \\ University of North Sumatra. \\ ${ }^{2}$ Undergraduate student, Departement of Biology, Faculty Mathematics and Natural Science, Universitas \\ Sumatera Utara, Jl. Bioteknologi No. 1 Kampus USU, Padang Bulan, Medan 2015, Sumatera Utara, \\ Indonesia.
}

\begin{abstract}
The effect quality leaves of mulberry (Morus australis) as nutrition for on silkworm (Bombyx mori L.) have been. This research was completely randomized design (CRD) with by two treatments. The first treatment was mulberry plants that was not cultivated with urea, triple super phosphate (TSP) and nitrogen, phosfor and pottasium (NPK) fertilizer. Tthe second treatment was the plants fertilized with urea, TSP and NPK. Each treatment was replicated 20 times. The results showed that the addition of urea, TSP and NPK fertilizer on mulberry had significantly affected $(p<0.05)$ on the value of the growth rate (GR) and the consumption rate (CR) of instars III and IV, whereas efficiency of conversion of digested food (ECD), efficiency of conversion of ingested food (ECI) and approximate digestibility (AD) in of instar III, IV and V were not significantly affected $(\mathrm{p}>0.05)$. The addition of urea, TSP and NPK fertilizer on mulberry increase the value of GR and CR instars III and IV as much as $31.15 \%, 38.46 \%$ and $49.27 \%, 33.67 \%$ respectively.
\end{abstract}

Keyword: Bombyx mori L., fertilizer, Morus australis, nutrition

Received 15 June, 2020 | Revised 3 August, 2020 | Accepted 25 August, 2020

\section{Introduction}

The Bombyx mori L. silkworm is a type of silkworm that is now widely cultivated by people in Indonesia. The growth of this type of silkworm is strongly influenced by feed, climatic conditions and the environment including temperature, humidity, light and air flow [1] and according to Samsijah \& Kusumaputra [2] B. mori L. is a type of insect that has value high economical for human, namely, a manufacturer major silk fibers. The effect of silkworm feed in

*Corresponding author at: Jl. Bioteknologi No. 1 Kampus Univ. Sumatera Utara, Padang Bulan, Medan, Indonesia

E-mail address: masittatanjung@yahoo.co.id 
the form of mulberry leaves reaches $38-40 \%$ of all the factors that influence the success of silkworm maintenance [3]. One of the varieties of mulberry superior namely Morus australis [4] and the Institute for Natural Silk [5] states that M. australis have better growth properties compared to other mulberry species.

In line with the government's efforts to increase the production of silk thread, it is necessary to make a breakthrough in silkworm cultivation. One effort is the provision of inorganic fertilizer is fertilizer urea, triple superphosphate (TSP) and nitrogen, phosphor and potassium ( NPK ) on M. australis. The fertilizer has a very important role on the growth and production of crops that might be expected to increase the nutritional index silkworm B. mori L. [6]. The nutritional index is a value that describes the state in the insect's body when the insect eats a certain type of food [7]. This study aims to determine the mulberry leaf feeding M. australis results of fertilization u rea, TSP and NPK against nutritional index silkworm B . mori L.

\section{Materials and Methods}

Research Model used was experimental research ( experimental research ) with Completely Randomized Design (CRD) consists of 2 treatment is treatment plant Morus australis without any manure and fertilizers with the symbol P0 $=$ without fertilizer and P1 = given fertilizer . Each treatment consisted of 20 test animals as replications.

Mulberry plantation land measuring 10x3 $\mathrm{m}$ which was in front of Tridarma Forest, Universitas Sumatra Utara divided into 2 of land cultivated and land without fertilizer each respective area of $5 \times 3 \mathrm{~m}$. M foreigners each land te rsebut processed as deep as 30-50 cm and d ibuat bed ith 5$10 \mathrm{~cm}$. Mulberry (M. australis) cuttings were obtained in the Kacinambung Village, District Kabanjahe, Karo District, Province of North Sumatra with cutting which 20-25 cm with 4-5 buds of fruit. One end of the cuttings is cut into $\pm 1.5 \mathrm{~cm}$ taper and the other end is horizontal and planted. That plants cuttings which has been planted, nurtured and fertilizer by spreading manure in the round mulberry plants with a dose of fertilizer in Table 1.

Table 1. Dose of Mulberry Fertilization

\begin{tabular}{ccccc}
\hline $\begin{array}{c}\text { Type of } \\
\text { Fertilizer }\end{array}$ & $\begin{array}{c}\text { Nutrient } \\
\text { Content }\end{array}$ & $\begin{array}{c}\text { Content } \\
\text { (\%) of } \\
\text { Nutrients }\end{array}$ & $\begin{array}{c}\text { Fertilization Dose } \\
\text { (kg/ha) }\end{array}$ & $\begin{array}{c}\text { Fertilization Dose } \\
\left.\text { Conversion (kg/m } \mathbf{m}^{\mathbf{2}}\right)\end{array}$ \\
\hline Urea & $\mathrm{N}$ & $46 \% \mathrm{~N}$ & 210 & 0.32 \\
TSP & $\mathrm{P}$ & $36 \% \mathrm{P}$ & 100 & 0.15 \\
N, P, K & N, P, K & $\begin{array}{c}16 \% \mathrm{~N}, \\
16 \% \mathrm{P},\end{array}$ & 260 & 0.39 \\
& & $16 \% \mathrm{~K}$ & & \\
\hline
\end{tabular}

(Note: Nature Research Center [3])

Silkworm eggs was found from Breeding Center of Silkworm (PPUS) Candiroto, Central Java. The eggs were put into white HVS paper, folded with carbon paper and arranged in a plastic basket until they hatched. The newly hatched sute ra were divided into two treatment groups, 
namely silkworms which were fed with mulberry leaves which is given fertilizer and without fertilizer, each consisting of 20 caterpillars and put in a petri dish that has been previously coated with wet tissue and pad paper.

At the end of the second instar, the caterpillars that have stopped eating are placed separately until they replace the cuticles (molting). After changing the cuticle, the caterpillar enters the initial third instar and is weighed. Feed mulberry leaves that $t$ anamannya fertilizers and without fertilizers weighed before being given first. At the end of the third instar, which is marked by the caterpillar having stopped eating and changing its cuticles, the silkworm rearing site is cleaned, removing feces and food residue. At the end of the third instar, the silkworms are weighed. The feces and feed residue produced by the caterpillars are then collected and dried in an oven at $60^{\circ} \mathrm{C}$. The same is done at the beginning and end of instar IV to instar V.

The parameters of the nutritional index from Waldbauer [8] which have been modified by Scriber \& Slansky [9] are:

- Larval growth rate (Growth rate/GR) .

$$
\mathrm{GR}=\mathrm{G} / \mathrm{TW}(\mathrm{mg} / \text { day })
$$

- The rate of consumption of the larvae (Consumption Rate/CR)

$$
\mathrm{CR}=\mathrm{F} / \mathrm{TW} \text { (mg/day) }
$$

- Efficiency of conversion of digested feed (Efficien cy of Conversion of Digestion d Food/ECD)

$$
\mathrm{ECD}=\mathrm{G} /(\mathrm{F}-\mathrm{E}) \times 100 \%
$$

- The efficiency of conversion of feed eaten by the larvae (E fficiency of C onversion of ingested Food / ECI)

$$
\mathrm{ECI}=\mathrm{G} / \mathrm{F} \times 100 \%
$$

- Estimates of feed ingested (Approximate Digesstibility/AD)

$$
\mathrm{AD}=(\mathrm{F}-\mathrm{E}) / \mathrm{F} \times 100 \%
$$

Information:

$\mathrm{G}=$ Weight gain of larvae during instar III-V, E = weight of faeces produced by larvae during instar III-V, F = weight of feed eaten by larvae during instar III-V, T = length of feeding period during instar III-V, W = Average weight of larvae during III-V instar . All of the above calculations are calculated in dry weight .

The data obtained from each parameter (variable) of observation are recorded and arranged in tabular form. The quantitative data (dependent variable) obtained were tested for their significance on the effect of the treatment group (independent variable) with the help of a computer statistical program, namely the statistical package for the social sciences (SPSS) release 16 program. The test sequence begins with a normality test, a homogeneity test. If the test results show $\mathrm{p}<0.05$ then the data is transformed and followed by a non-parametric test 
(Mann-Whitney) and if the test results show $\mathrm{p}>0.05$ then the data is analyzed by parametric test (T test).

\section{Result and Discussion}

\section{Growth Rate (GR) of Instar Silkworm III, IV and V}

The results of the calculation of the growth rate of instar III, IV and V silkworms on mulberry treated with fertilizer and without fertilizer can be seen in Figure 1.

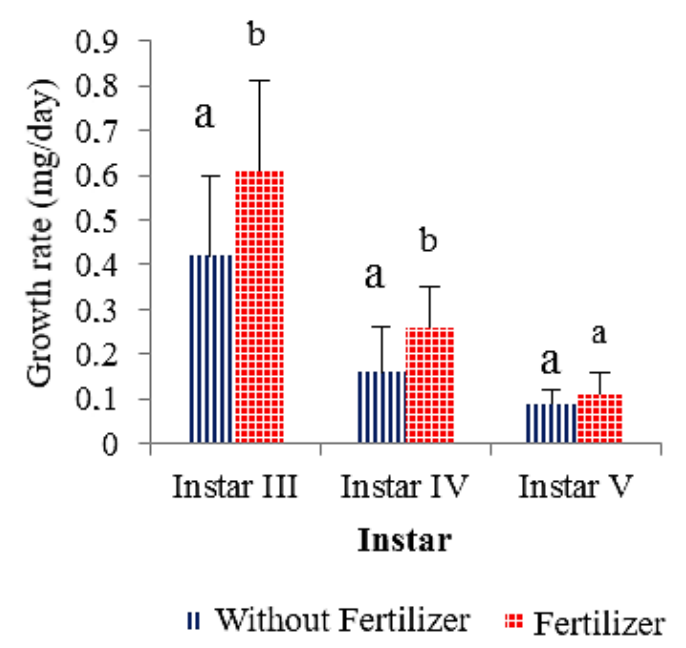

Figure 1. The average growth rate of Bombyx mori L. silkworms fed mulberry leaves with fertilizer treatment and without fertilizer during instar III, IV and V. The same letter in the same observation was not significantly different at the $5 \%$ level $(\mathrm{p}>0.05)$.

The growth rates of silkworms at instar III \& IV showed a significant difference between fertilizer treatment and without fertilizer $(p<0.05)$, while the growth rate of silkworms at instar III was not significantly different $(\mathrm{p}>0.05)$ and silkworms consuming mulberry leaves were given fertilizer resulted in a higher growth rate (Figure 1). The application of Urea, TSP and NPK fertilizers caused changes in the nutritional content of mulberry leaves. The nutritional content is in the form of protein, carbohydrates, fat, water and ash. Ash is related to the mineral content of mulberry leaves. Protein, carbohydrates and ash in fertilized mulberry leaves produced relatively higher values than those on un fertilized mulberry leaves, while fat and water resulted in low values for fertilized mulberry leaves. The relatively higher protein, carbohydrate and ash content as well as a lower fat and water content are consumed by silkworms, resulting in high growth. It requires relatively large carbohydrates, protein and minerals as well as low fat content and relatively low water content from the mulberry leaves to accelerate the process of growth and development [2][10].

\section{Consumption Rate (CR) of Instar Silkworm III, IV and V}


The results of the calculation of the consumption rate of instar III, IV and V silkworms on mulberry plants $M$. australis treated with fertilizers and without fertilizers can be seen in Figure 2.

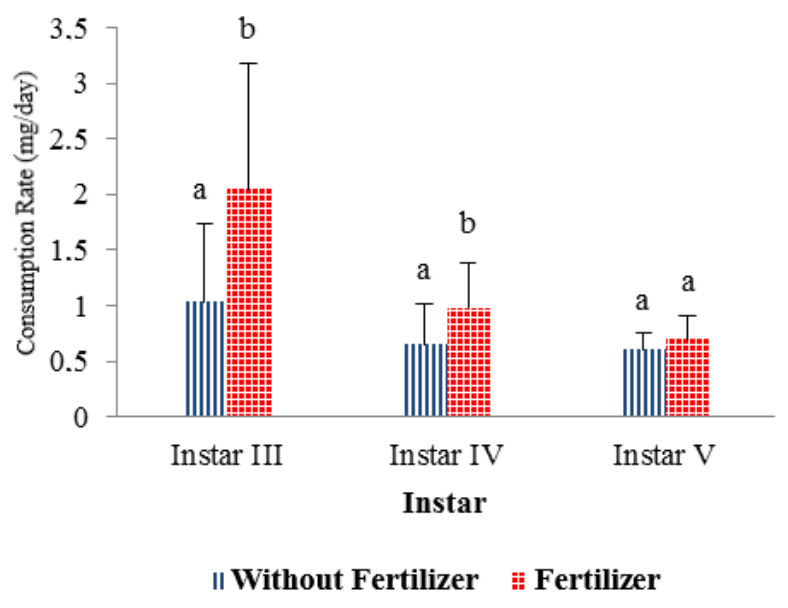

Figure 2 . The average consumption rate (CR) of silkworm Bombyx mori L. by mulberry leaves with treatment without fertilizer and fertilizer during NSTAR III, IV and V. The letters together on the same observations are not different from the real to the level of $5 \%(p>0.05)$.

The consumption rate of silkworms at instar III \& IV showed a significant difference between fertilizer treatment and without fertilizer $(\mathrm{p}<0.05)$, while at instar $\mathrm{V}$ was not significantly different $(p>0.05)$. Silkworms consuming fertilized mulberry leaves resulted in a higher consumption rate (Figure 2). This is because mulberry plants that are given fertilizer have a relatively higher nutrient content in the form of carbohydrates, protein and ash so that the caterpillars consume more mulberry leaf feed, whose plants are fertilized. The relatively higher carbohydrates, protein and ash in mulberry leaves whose plants are fertilized are used by silkworms for their growth and development processes. According to Tazima [11], good feed in addition to having complete nutritional or nutritional content that is used for larval growth, must also have a good taste so that the larvae will consume a lot of the feed while the food that lacks a good taste, the larvae are reluctant to consume the feed. the .

\section{Efficiency of Digestive Feed Conversion (ECD) Silkworm Instar III, IV and V}

The results of the calculation of the efficiency of feed conversion digested by instar III, IV and V silkworms on M. australis mulberry plants treated with fertilizers and without fertilizers can be seen in Figure 3.

The results showed that the value of the conversion efficiency of ingested feed in the fertilizer treatment was higher than in the treatment without fertilizer, although there was no significant difference $(\mathrm{p}>0.05)$ in the third, IV and V instar silkworms between the fertilizer treatment and without fertilizer (Figure 3) . 


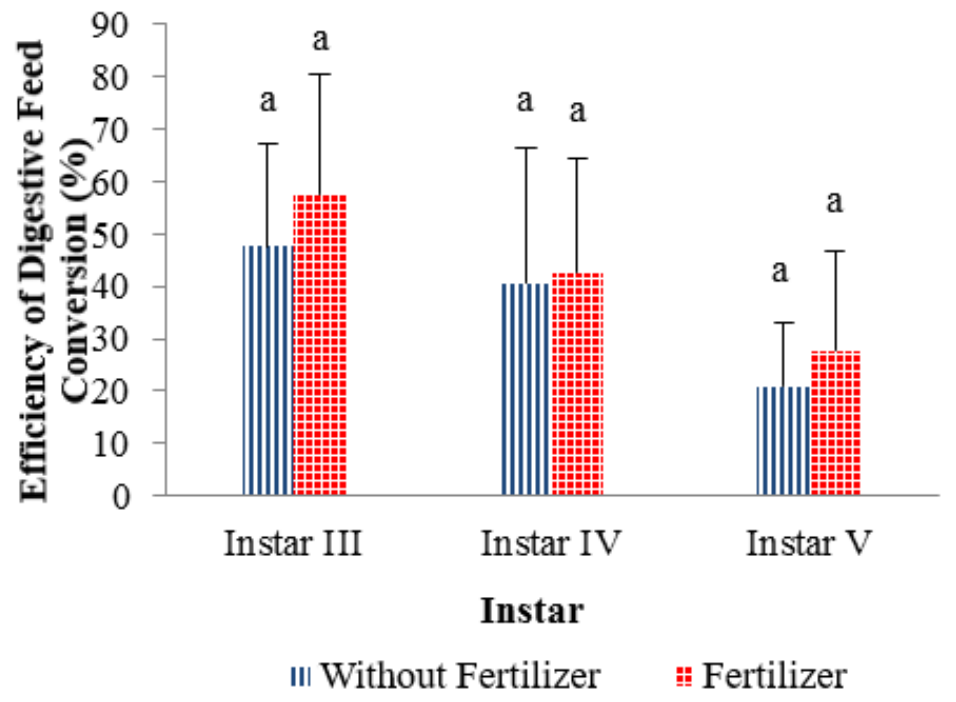

Figure 3. Mean ECD value silkworm Bombyx mori L. were given leaves of mulberry with fertilizer treatment and no fertilizer during instar III, IVdan V. Same letter on the observation that the same is not significantly different at the level of $5 \%(p>0.05)$.

This shows that fertilized feed is better than non-fertilized feed. This means that silkworms in the mulberry leaf treatment that are given fertilizer are able to effectively and efficiently utilize the nutrients absorbed for metabolic processes in the body as a result manifested in high growth as well. According to Paul et al., [12], which consumes silkworms mulberry leaves with a high nutrient content will produce higher growth and will easily be absorbed by the body of silkworms for the continuity of life.

\section{Efficiency of Edible Feed Conversion (ECI) Silkworm Instar III, IV and V}

The results of the calculation of the efficiency of feed conversion eaten by instar III, IV and V silkworms on mulberry plants treated with fertilizers and without fertilizers can be seen in Figure 4.

The results showed that the value of the conversion efficiency of the feed eaten in the fertilizer treatment was higher than in the treatment without fertilizer, although there was no significant difference $(\mathrm{p}>0.05)$ in the third, IV and V instar silkworms between the fertilizer treatment and without the fertilizer (Figure 4). The application of Urea, TSP and NPK fertilizers to mulberry plants causes the nutrient content in the form of carbohydrates, protein and ash in the mulberry leaves to be relatively higher so that the silkworms consume more mulberry leaves that are given fertilizer. With the large number of caterpillars consuming mulberry leaves that are given fertilizer, the caterpillar growth is also getting bigger so that the caterpillars are more efficient in utilizing food, which is reflected in the growth and consumption of large caterpillars. According to research conducted by Hariani et al., [13], Spodoptera exigua insects that consume green mustard feed which have relatively high nutritional content produce high ECI values . 


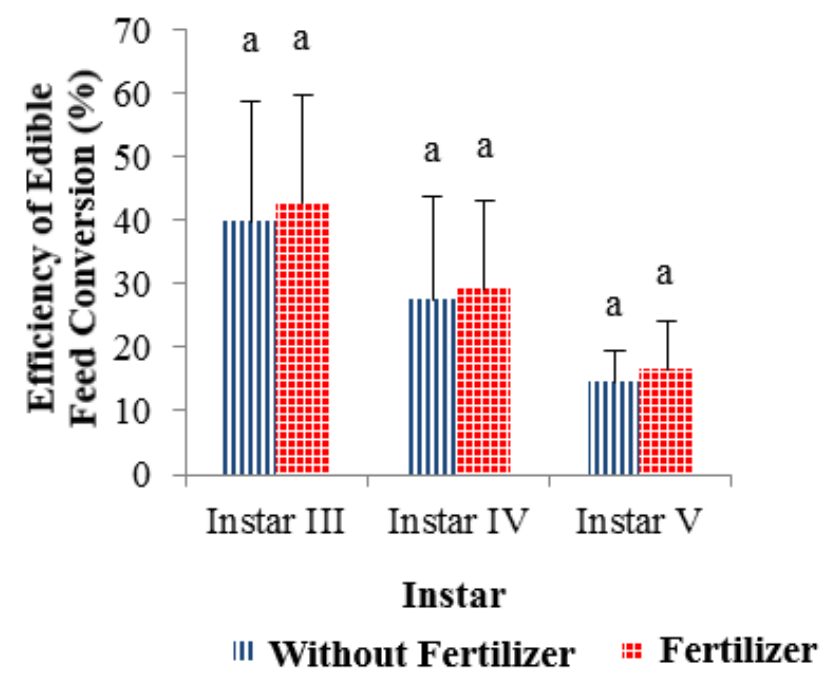

Figure 4 . The mean value of ECI silkworm Bombyx mori L. were given leaves of mulberry with fertilizer treatment and no fertilizer during instar III, IV and V. The same letters in observation the same is not significantly different at the level of $5 \%(p>0.05)$.

The value of the edible feed conversion efficiency (ECI) varies depending on the food digested and the proportion of the amount of food that is (1) converted into body mass, (2) is metabolized to produce energy for growth and development [10]. In addition, the ECI value is influenced by the increase in body weight and dry weight of the feed consumed.

\section{Estimated Feed Digest (AD) Silkworm Instar III, IV and V}

The results of the calculation of the estimated feed ingested by instar III, IV and V silkworms on mulberry plants (M. Australis) treated with fertilizers and without fertilizers can be seen in Figure 5.

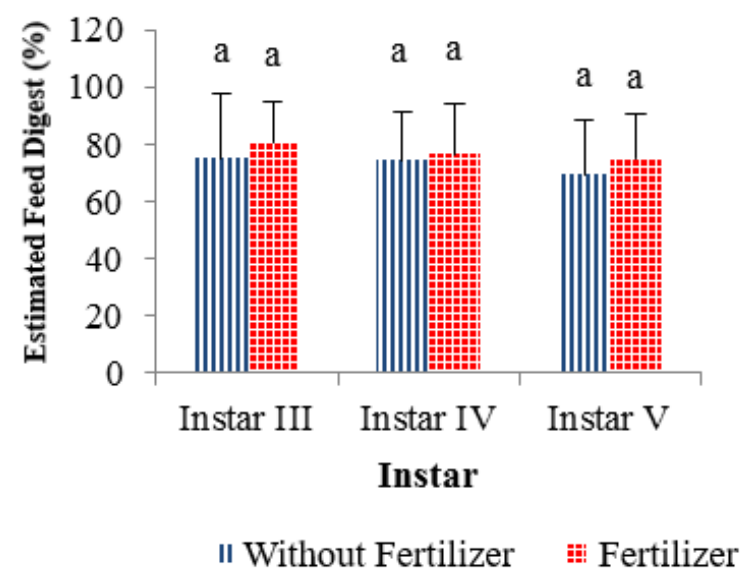

Figure 5. The mean value of AD Silkworm Bombyx mori L. yan g given mulberry leaves with treatment fertilizer and without fertilizer during instar III, IV and V. The letters at the observation that the same is not significantly different in $t$ araf $5 \%(p>0.05)$.

The results showed that the estimated values of ingested feed on mulberry leaves with fertilizer and mulberry leaves without fertilizers showed no significant difference ( $p>0.05$ ) for third, IV 
and $\mathrm{V}$ instar silkworms between fertilizer treatments. and without fertilizer (Figure 5). The digestibility value of each caterpillar on fertilizer and without fertilizer was above $50 \%$. This shows that mulberry leaves treated with Urea, TSP and NPK fertilizers and without fertilizers are easily digested by the silkworms. This is in line with the research conducted by Ahmad et al., [14] that mulberry leaves with different nutritional content are easily digested by silkworms as indicated by an $\mathrm{AD}$ value of $53-87 \%$. According to Kerkut \& Lawrence [15], the amount of food that can be digested is not all converted into body weight but some are used to maintain larval survival and also for cocoon formation. The approximate value of digestion (AD) is influenced by other factors, namely the rate of trip food through the intestines, the content of the material can digested, weight dry matter feed and faeces produced [8].

\section{Comparison of Growth Rate (GR) and Consumption Rate (CR) of Instar Silkworm III, IV and $\mathrm{V}$}

Comparison of the value of growth rate (GR) and consumption rate (CR) of III, IV and V instar silkworms on mulberry plants (M. australis) treated with fertilizers and without fertilizers can be seen in Figure 6.

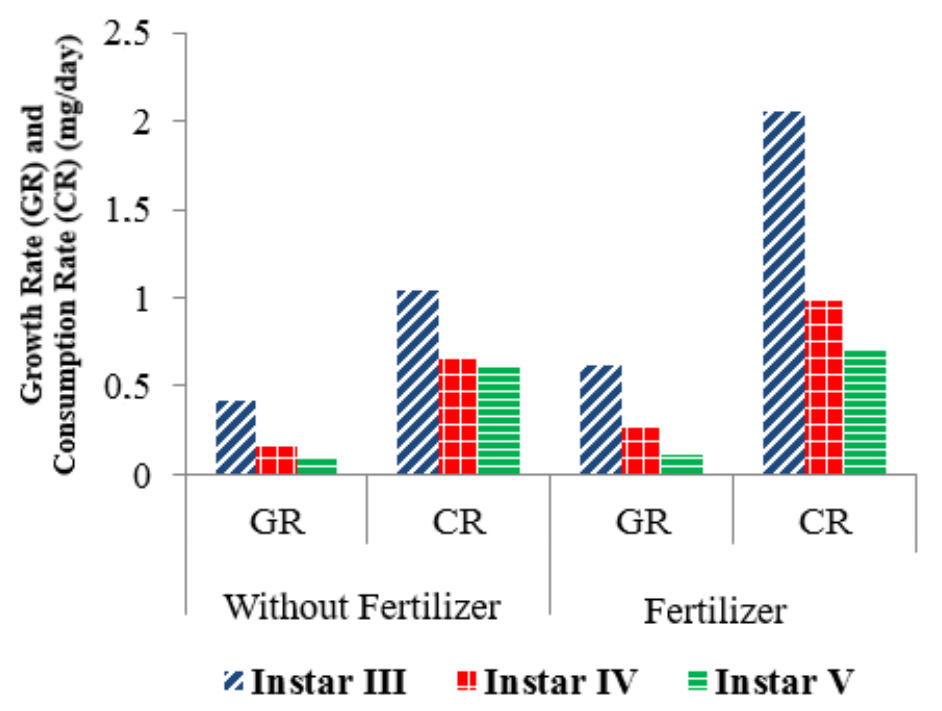

Figure 6. The mean value of GR and CR silkworm Bombyx mori L. were given mulberry leaves treated with fertilizer and no fertilizer during instar III, IV and V.

The highest growth rate in fertilizer and without fertilizer treatment was third instar silkworm, while the smallest growth rate was V instar silkworm. This is because third instar silkworms, which are still classified as small caterpillars, consume more food for growth. the large caterpillar phase, while the $\mathrm{V}$ instar silkworm is classified into the large caterpillar phase where the food eaten is not used for growth anymore but for food reserves during cocoon formation and turns into a pupae . 
Its highest consumption rate for fertilizer and without fertilizer treatment was third instar silkworm, while the lowest consumption rate was for V instar silkworm. This is in line with the decreasing growth rate. Third instar silkworms require a large consumption rate as a source of energy to use the silkworms to the next stage of development, while the $\mathrm{V}$ instar silkworms which will enter the cocoon phase and pupa experience a lot of resting phase so that the caterpillars do not consume a lot of mulberry leaves which are given which results in the rate. consumption is decreasing.

\section{Comparison of Digestible Feed Conversion Efficiency (ECD), Edible Feed Conversion Efficiency (ECI) and Estimated Digested Forage (AD) Instar Silkworm III, IV and V}

Comparison of digested feed conversion efficiency (ECD), edible feed conversion efficiency (ECI) and estimated feed digested (AD) III, IV and V instar silkworms on mulberry plants ( $M$. australis) treated with fertilizers and without fertilizers can be seen in Figure 7.

ECD value in the treatment of fertilizer and without fertilizer greatest is at the third instar silkworms while ECD smallest value in V. instar silkworm conversion efficiency of feed ingested indicates the feed is assimilated to grow as energy metabolism. Third instar silkworms, which are classified as small caterpillars, still require relatively small metabolic energy to turn into large caterpillars, resulting in a large feed conversion efficiency value, while $\mathrm{V}$ instar silkworms which are classified as large caterpillars require relatively large metabolic energy to reach the curing phase. and pupae, resulting in small feed conversion efficiency values. According to Beament et al., [16], the amount of metabolic energy required by silkworms is reflected in the low efficiency of digestion of feed conversion.

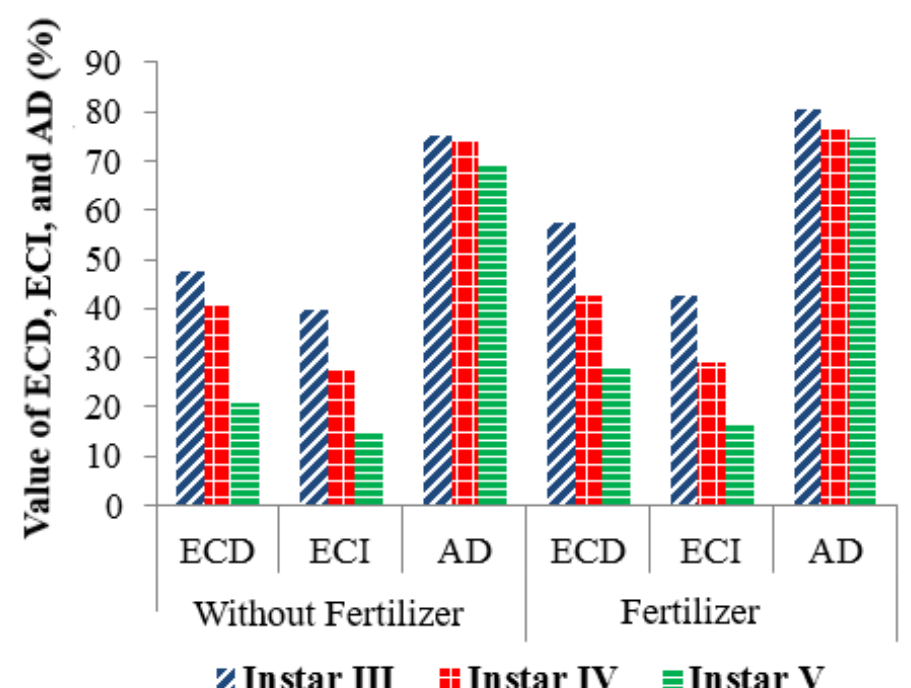

Figure 7. The mean value of ECD, ECI and AD silkworm Bombyx mori L. were given mulberry leaves premises $\mathrm{n}$ treatment of fertilizer and no fertilizer during instar III, IV and V. 
The ECI value on fertilizer treatment and without fertilizer was the greatest for third instar silkworms, while the smallest ECI value was for V instar silkworms. This is because third instar silkworms use food for growth to the adult stage as reflected by the large consumption rate whereas $\mathrm{V}$ instar silkworms are mostly feed used for metabolic processes and for silk synthesis.

The $\mathrm{AD}$ value in fertilizer treatment and without fertilizer was the largest in instar III silkworms, while the smallest $\mathrm{AD}$ value was in $\mathrm{V}$ instar silkworms. This is presumably because third instar silkworms choose young leaves to eat while instar IV and V prefer to eat. old or slightly old leaves. This results in an increase in the proportion of fiber in the leaves that are difficult for the larvae to digest so that the $\mathrm{AD}$ value decreases.

Reflected on an fertilizers urea, TSP and NPK on mulberry increase the value of the growth rate (GR) and the consumption rate (CR) in the third and fourth instars respectively by $31.15 \%$; $38.46 \%$ and $49.27 \% ; 33.67 \%$ while the value of the digestible feed conversion efficiency (ECD), the conversion efficiency of the feed eaten (ECI) and the estimated feed ingested (AD) did not show a significant effect on instars III, IV and V.

\section{Conclusion}

The addition of urea, TSP and NPK fertilizer on mulberry increase the value of GR and CR instars III and IV as much as $31.15 \%, 38.46 \%$ and $49.27 \%, 33.67 \%$ respectively.

\section{REFERENCES}

[1] Setiana, H. Practical Instructions for Silkworm Cultivation. Central Java: Perum Perhutani. p. 1. 2006.

[2] Samsijah , Kusumaputra S. Maintenance of Silkworm Bombyx mori L . Bogor: Forest Research Institute. 1975.

[3] Nature Research Center. Mulberry Cultivation Technical Instructions (Morus spp.). South Sulawesi Forestry Department. p. 1, 6-12. 2007.

[4] Lamangantjo, CJ. Development of silkworm population (Bombyx mori L.) and the quality of silkworms in several types of mulberry . Eugenia's Journal. 9 (1): 47-48. 2003.

[5] Natural Silk Center. Instructions Technical Cultivation Murberry (Morus spp.) . South Sulawesi Forestry Department .p. 1, 6-12. 2007.

[6] Rauf, A. W ., Syamsuddin T ., Sri R. S. The role Pup uk NPK At Rice plant . Irian Jaya: Ministry of Agriculture. 2000.

[7] Herliana, E. Effect of fertilizer on the quality of silkworm cocoons (Bombyx mori L.). [Thesis]. Bogor: Faculty of Forestry. Bogor Agricultural Institute. p. 3-6. 2008.

[8] Waldbauer, GP, Cohen, Friedman RW S. An improved procedure of e for laboratory rearing of the corn earworm, Helothis zea (Lepidoptera : Noctuidae). J urnal The Great Lakes Entomologies .87 (2): 305-306. 1984. 
[9] Scriber, J. M. , Slansky F. Jr. The Nutritional ecology Of Immature Insects . Ma dison: Department of Entomology, University of Wisconsin . p. 183-184. 1981.

[10] Horie, Y. Quantitative Requirement of Nutrients for Growth of Silkworms . Tokyo: Japan Agricultural Research Quarterly. 1978.

[11] Tazima. The Silkworm: An Important Laboratory Tool . Tokyo: Kodansha. p. 31-35. 1978.

[12] Paul, D. C. , Rao GS , Deb DC. Impact of d ietary moistu re on nutritional indices and growth of Bombyx mori and concomitant larval duration. Jurna 1 Insect Physiology. 38 (1): 229-231. 1992.

[13] Hariani, N., Diamond A., Resti R . Efficiency of eating Spodoptera exigu a (Lepi doptera: Noctuidae) on leeks, mustard greens and celery in the laboratory. Journal of Natur Indonesia. 14 (1): 89. 2011.

[14] Ahmad, I., A meiria DL, Soelaksono S. Food utilization parameters could be used to indicate foo d suitability in the silkworm, Bomby x mori . Journal of Bioscience . 1 (1): 6. 1995.

[15] Kerkut, GA, Lawrence IG. Regulation digestion nutrition excretion. Journal of Comprehensive Insect Physiology Biochemistry and Pharmacology. 1 (4): 393. 1988.

[16] Beament, JWL, JE Treherne, Wiglesworth V . B. Advances in Insect Physiology . Volume 5. London and New York: Academy Press. p. 142-145. 1968. 